\title{
4-Methoxycinnamic acid - An unusual phenylpropanoid involved in phenylphenalenone biosynthesis in Anigozanthos preissii
}

\author{
William Hidalgo, Marco Kai, Bernd Schneider* \\ Max-Planck Institut für Chemische Ökologie, Beutenberg Campus, Hans-Knöll-Strasse 8, 07745 Jena, Germany
}

\section{A R T I C L E I N F O}

\section{Article history:}

Available online 25 July 2015

\section{Keywords:}

Anigozanthos preissi

Wachendorfia thyrsiflora

Biosynthesis

Haemodoraceae

Labeling

Nuclear magnetic resonance

Phenylphenalenones

Phenylpropanoids

\begin{abstract}
A B S T R A C T
In vitro root cultures of Anigozanthos preissii and Wachendorfia thyrsiflora (Haemodoraceae) are suitable biological systems for studying the biosynthesis of phenylphenalenones. Here we report how we used these root cultures to investigate precursor-product relationships between phenylpropanoids and phenylphenalenones whose phenyl rings share identical substitution patterns. Four phenylpropanoic acids, including ferulic acid and the unusual 4 -methoxycinnamic acid, were used in ${ }^{13} \mathrm{C}$-labeled form as substrates to study their incorporation into phenylphenalenones. In addition to the previously reported 2hydroxy-9-(4'-hydroxy-3'-methoxyphenyl)-1H-phenalen-1-one (trivial name musanolone F), 2-hydroxy-9-(4'-methoxyphenyl)-1H-phenalen-1-one (proposed trivial name $4^{\prime}$-methoxyanigorufone) was found as a biosynthetic product in A. preissii. The carbon skeleton of $4^{\prime}$-methoxycinnamic acid was biosynthetically incorporated as an intact unit including its $4^{\prime}$-O-methyl substituent at the lateral phenyl ring. 4'-Methoxyanigorufone is reported here for the first time as a natural product.
\end{abstract}

(c) 2015 Published by Elsevier Ltd.

\section{Introduction}

Phenylphenalenones are a characteristic class of secondary metabolites occurring in the monocotyledoneous plant families Haemodoraceae, Pontederiaceae, Strelitziaceae and Musaceae (Munde et al., 2013). They are polycyclic aromatic compounds consisting of a tricyclic phenalene core structure with a keto functional group and a lateral phenyl ring (ring D) (see structure in Table 1). Because of their fungicidal (Otálvaro et al., 2007; Hidalgo et al., 2009) and nematicidal properties (Hölscher et al., 2014) and their inducibility after pathogen/herbivore attack (Luis et al., 1994; Jitsaeng and Schneider, 2010; Otálvaro et al., 2010), phenylphenalenones play an important role as phytoalexins in the chemical defense of Musa plants. The physiological and/or ecological importance of these metabolites in the three other plant families has yet to be explored, although their antioxidant capacity could be one of the reasons they are produced (Blokhina et al., 2003; Duque et al., 2010; Brewer, 2011).

Previous biosynthetic studies have demonstrated that phenylphenalenone-type compounds are formed by the condensation of two phenylpropanoids merged with one malonate unit through the diarylheptanoid pathway. The variable substitution pattern of

DOI of original article: http://dx.doi.org/10.1016/j.phytochem.2015.05.017

* Corresponding author.

E-mail address: schneider@ice.mpg.de (B. Schneider). the lateral phenyl ring (ring D: unsubstituted phenyl; 4'-hydroxyphenyl; 3',4'-dihydroxyphenyl; 3'-methoxy-4'-hydroxyphenyl) contributes to the structural diversity of the phenylphenalenones (Hölscher and Schneider, 1995a,b; Schmitt et al., 2000). As previously demonstrated in Anigozanthos preissii, the substitution pattern of ring $D$ reflects the substitution pattern of the phenylpropanoid precursors (Schmitt et al., 2000). Four phenylpropanoids have been identified so far as precursors of a C-9 moiety comprising ring $D$ and three adjacent carbon atoms C-7 to C-9 of the phenalenone tricycle (for details see Table 1 ). In the case of $4^{\prime}-O$ methylirenolone, which has a methoxy group in position $4^{\prime}$ of ring $\mathrm{D}$, the actual phenylpropanoid precursor could not be determined because 4'-methoxycinnamic acid (2), when administered to in vitro plants of Musa acuminata, was demethylated and further converted to $3^{\prime}, 4^{\prime}$-methylenedioxyphenylpropanoic acid (Otálvaro et al., 2010). Hence, due to their strong demethylation capacity for exogenously supplied $4^{\prime}$-methoxycinnamic acid, Musa plants seemed to be unsuitable for studying the suggested biosynthetic precursor-product relationship between methoxyphenylpropanoids and phenylphenalenones with methoxy-substituted ring $\mathrm{D}$, such as $4^{\prime}-O$-methylirenolone.

In vitro root cultures of $A$. preissii and Wachendorfia thyrsiflora (both belonging to the Haemodoraceae plant family), which are suitable biological systems for studying the biosynthesis of phenylphenalenones (Hölscher and Schneider, 1995b; Schmitt et al., 2000; Munde et al., 2013), produce pairs of phenylpropanoids 
Table 1

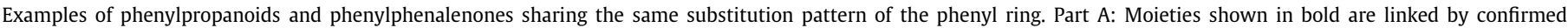

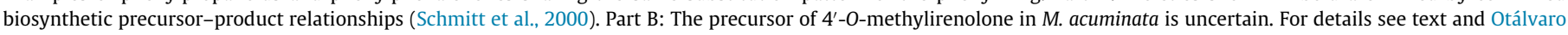
et al. (2010).

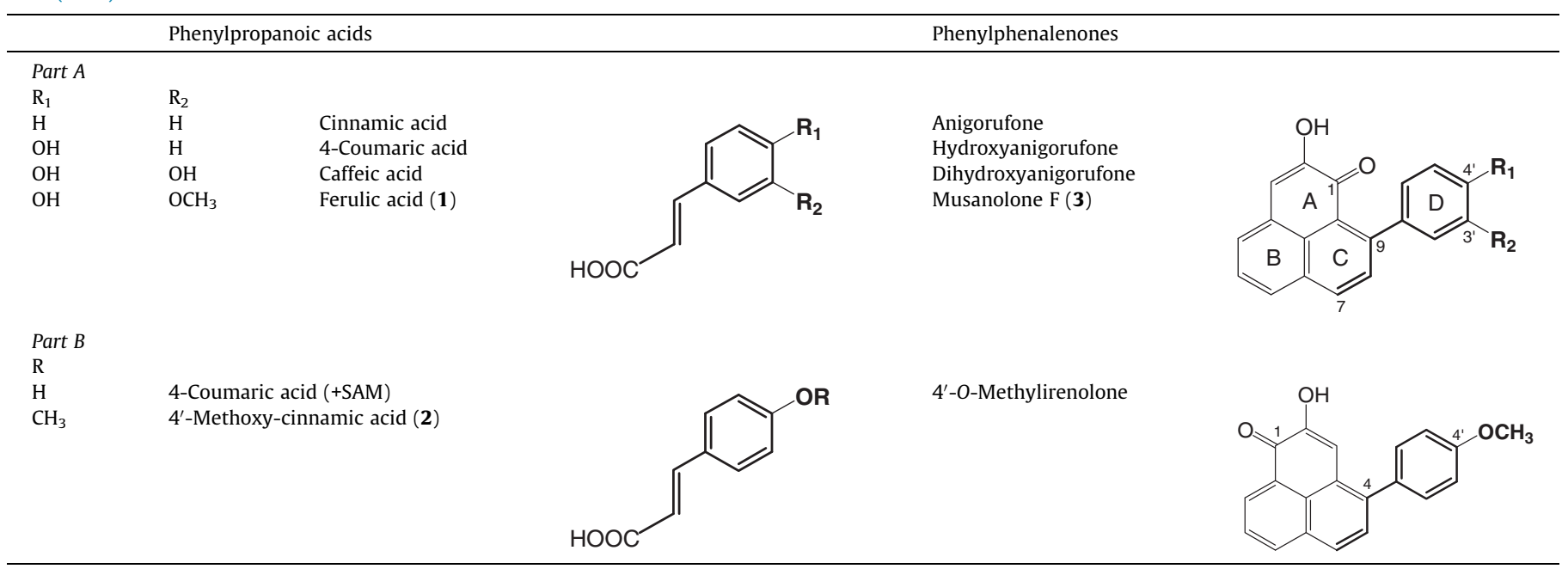

SAM = S-adenosyl-L-methionine .

and phenylphenalenones with corresponding methoxy-substituted phenyl ring substitutions. Here we report the ${ }^{1} \mathrm{H}$ NMR and HPLCguided identification of phenylpropanoic acids using an isotope dilution approach. In the second part of this work, we offer evidence for a precursor-product relationship by administering the ${ }^{13} \mathrm{C}$-labeled phenylpropanoids then isolating the resulting phenylphenalenones and analyzing its ${ }^{13} \mathrm{C}$ enrichment by ${ }^{13} \mathrm{C}$ NMR and HRMS.

\section{Results and discussion}

\subsection{Detection of phenylpropanoic acids in plant root cultures}

In vitro root cultures of $A$. preissii and $W$. thyrsiflora are rich sources of phenylphenalenones (Hölscher and Schneider, 1997; Opitz et al., 2002; Opitz and Schneider, 2003; Fang et al., 2011) and therefore were selected for the present study. However, only one compound of that type, 2-hydroxy-9-(4'-hydroxy-3'-methoxyphenyl)-1H-phenalen-1-one (musanolone $\mathrm{F}(3)$ ), which has a methoxylated lateral phenyl ring $\mathrm{D}$, was reported from $A$. preissii (Schmitt et al., 2000). Musanolone F (3) is biosynthetically derived from ferulic acid (1), which is an abundant phenylpropanoic acid in A. preissii (Schmitt and Schneider, 2001). Most of the phenylphenalenones occurring in $W$. thyrsiflora have an unsubstituted ring D (Fang et al., 2011, 2012), and no compound with a methoxy substituent in ring $\mathrm{D}$ has yet been reported from this plant. Also no data about the occurrence of phenylpropanoic acids in $W$. thyrsiflora are available.

We synthesized $\left[2-{ }^{13} \mathrm{C}\right]$ ferulic acid $\left(\left[2-{ }^{13} \mathrm{C}\right]-\mathbf{1}\right),\left[2-{ }^{13} \mathrm{C}\right]$ isoferulic acid, $\left[2-{ }^{13} \mathrm{C}\right] 4^{\prime}-$ methoxycinnamic acid $\left(\left[2-{ }^{13} \mathrm{C}\right]-2\right)$, and $\left[2-{ }^{13} \mathrm{C}\right] 3^{\prime}, 4^{\prime}-$ methylenedioxycinnamic acid and used an isotope dilution approach to analyze the two plant systems for the occurrence of these phenylpropanoic acids. Although compound $\mathbf{1}$ is widely distributed in plants (Kroon and Williamson, 1999) including A. preissii (Schmitt and Schneider, 2001), isoferulic acid and 4'methoxycinnamic acid (2) are rarely found in plants (Liu et al., 1999; Sobolev et al., 2006; Kuddus et al., 2010). Free 3',4'methylenedioxycinnamic acid has to our knowledge been identified only in Piper philippinum (Chen et al., 2007) and M. acuminata (Otálvaro et al., 2010). The four $\left[2-{ }^{13} \mathrm{C}\right]$-labeled phenylpropanoids were separately administered to the two in vitro-root cultures. ${ }^{1} \mathrm{H}$
NMR and HPLC-guided isolation was used to identify ${ }^{13} \mathrm{C}$-labeled phenylpropanoic acids and their unlabeled native counterparts in the crude root extracts of both cultures.

The fingerprint signals of $\mathrm{H}-2$ of the $E$-configured double bonds $\left(J_{\mathrm{H} 2-\mathrm{H} 3}=16 \mathrm{~Hz}\right)$ and their ${ }^{13} \mathrm{C}$ satellite signals $\left(J_{\mathrm{C} 2-\mathrm{H} 2}=161 \mathrm{~Hz}\right)$ were used to detect isotopologue mixtures of non-metabolized $\left[2-{ }^{13} \mathrm{C}\right]-$ phenylpropanoids together with the unlabeled counterparts in the plant extracts. Using this approach, the natural occurrence of free ferulic acid (1) was confirmed in root cultures of $A$. preissii and detected for the first time in root cultures of $W$. thyrsiflora (Fig. 1A, B). 4'-Methoxycinnamic acid (2) was found in A. preissii but not in $W$. thyrsiflora (data not shown). Isoferulic acid and $3^{\prime}, 4^{\prime}$-methylenedioxy phenylpropanoic acid were not detectable in either of the two root cultures.

Moreover, the proportion of $\left[2-{ }^{13} \mathrm{C}\right]$-labeled and unlabeled phenylpropanoids was determined from the integral ratio of the doublets of $\mathrm{H}-2$ and the ${ }^{13} \mathrm{C}$ satellite signals in the ${ }^{1} \mathrm{H}$ NMR spectra (Schneider et al., 2003). Since the feeding experiments with $A$. preissii and $W$. thyrsiflora were performed under identical conditions, the integral ratios suggested a lower endogenous level of free ferulic acid (1) in $W$. thyrsiflora (ratio ${ }^{13} \mathrm{C}$-labeled: unlabeled 8.0: 1 ) compared to A. preissii $(2.7: 1)$. The isotopologue ratio of $\left[2-{ }^{13} \mathrm{C}\right]-2$ to unlabeled $\mathbf{2}$ (natural abundance ${ }^{13} \mathrm{C}$ contents) in $A$. preissii was found to be 8.1: 1 under the experimental conditions.

As ferulic acid (1) is a common cell wall lignin component (Buanafina, 2009), the proportion of this phenylpropanoic acid potentially available for the biosynthesis of phenylphenalenones is difficult to estimate. Unlike ferulic acid (1), 4'-methoxycinnamic acid (2) seems not to be used as a precursor in major plant metabolic pathways such as lignin formation. Therefore, all of the endogenous pool found in $A$. preissii should be available for the biosynthesis of phenylphenalenones. Hence, our search for methoxyphenylphenalenones and their biosynthesis was focused on $A$. preissii.

\subsection{Detection and biosynthesis of methoxyphenylphenalenones in plant root cultures}

The administration of $\left[2-{ }^{13} \mathrm{C}\right]$ ferulic acid (1) and $\left[2-{ }^{13} \mathrm{C}\right] 4^{\prime}-$ methoxycinnamic acid (2) resulted in their successful incorporation into the corresponding phenylphenalenones from A. preissii, 
$\mathbf{A}$
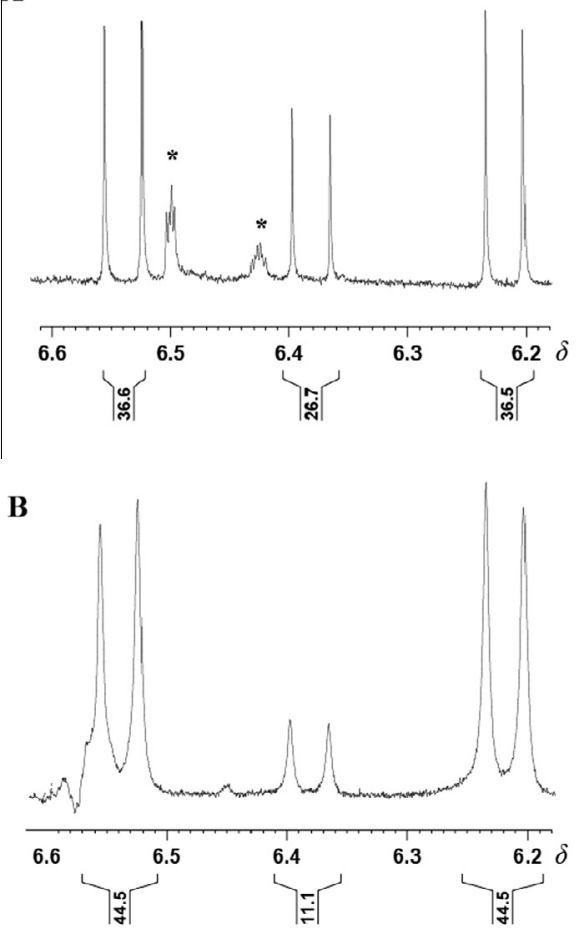

$\mathbf{C}$<smiles>[R6]Oc1ccc(/C=C(\N)C(=O)O)cc1[R20]</smiles>

D

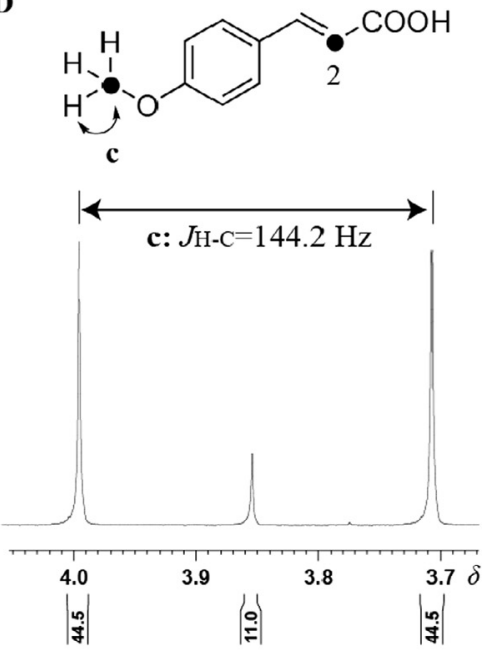

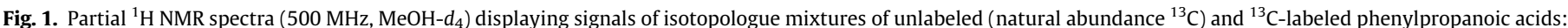

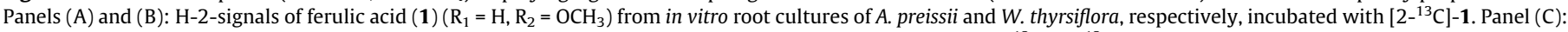

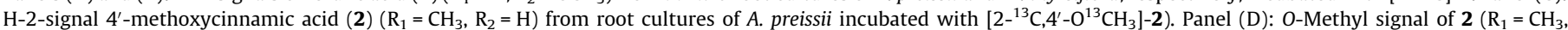

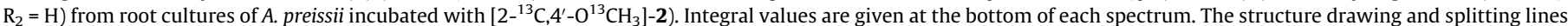

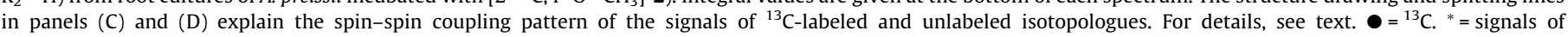
contaminations.

whereas no incorporation of $\mathbf{1}$ into any phenylphenalenone was detected in the case of $W$. thyrsiflora. Musanolone F (3) was the only phenylphenalenone isolated after $A$. preissii was incubated with $\left[2-{ }^{13} \mathrm{C}\right]-\mathbf{1}$, and its ${ }^{13} \mathrm{C}$ NMR spectra as well as the isotopologue analysis by HRESIMS (data not shown) are in accordance with the data previously reported (Schmitt et al., 2000). This leads us to conclude that the characteristic $3^{\prime}-\mathrm{OMe}, 4^{\prime}-\mathrm{OH}$ substitution pattern found in ring $\mathrm{D}$ of $\mathbf{3}$ is derived from $\mathbf{1}$.

The incubation of $A$. preissii root cultures with $\left[2-{ }^{13} \mathrm{C}\right] 4{ }^{\prime}$-methoxycinnamic acid (2) and ${ }^{13} \mathrm{C}$ NMR-guided fractionation indicated that an unknown metabolite had been enriched with ${ }^{13} \mathrm{C}$ (Fig. S1). This metabolite, which was subjected to HPLCguided isolation, was finally identified by $1 \mathrm{D}$ and $2 \mathrm{D}$ NMR and mass spectrometry as 2-hydroxy-9-(4'-methoxyphenyl)-1H-phenale-1-one (4). This compound, for which we propose the trivial name 4'-methoxyanigorufone, was previously synthesized and characterized by spectroscopic methods (Cooke and Dagley, 1978) and also found in Musella lasiocarpa (D. Hölscher, personal communication). Here $\mathbf{4}$ is reported for the first time as a naturally occurring phenylphenalenone. The ${ }^{13} \mathrm{C}$ NMR spectrum of $\mathbf{4}$ showed an enhanced signal at $\delta 132.6$ of C-8 in the phenylphenalenone skeleton (Fig. 2, panel b), and the isotopologue analysis carried out by HRESIMS indicated the enrichment of $53.7 \%{ }^{13} \mathrm{C}$ singly labeled molecule of $\left[8{ }^{13} \mathrm{C}\right] 2$-hydroxy-9-(4'-methoxyphenyl)- $1 \mathrm{H}$ phenale-1-one (4) biosynthesized from the administered $\left[2-{ }^{13} \mathrm{C}\right]$-labeled precursor $\mathbf{2}$ (Table 2 ).

This result clearly indicates a precursor-product relationship between 4 '-methoxycinnamic acid (2) and the new phenylphenalenone (4). However, it opens the question whether $\mathbf{2}$ was incorporated (after being activated to the SCoA ester) as an intact unit into 4'-methoxydiarylheptanoid and, further, whether $\mathbf{2}$ was incorporated into the phenylphenalenone $\mathbf{4}$ (early $\mathrm{O}$-methylation; route $i$ in Fig. 3). Alternatively an $O$-demethylation of $4^{\prime}$ methoxycinnamic acid (2) could have been involved (route ii in Fig. 3); such an $\mathrm{O}$-demethylation could have led to 4-coumaric acid which has been reported for being a precursor of the lateral phenyl ring in the phenylphenalenone skeleton (Funk and Brodelius, 1990; Hölscher and Schneider, 1995a). Route ii would require re-methylation of the 4'-OH group, probably at the stage of hydroxyanigorufone (late $O$-methylation) or the $4^{\prime}$-hydroxydiarylheptanoid (Fig. 3). This option was considered because in M. acuminata, the O-demethylation of 4 '-methoxycinnamic acid (2) was reported; however, no conclusive evidence was provided about whether the $4^{\prime}-\mathrm{O}$-methyl group of $4^{\prime}-\mathrm{O}$-methylirenolone, an isomer of $\mathbf{4}$, is the result of an early or a late $O$-methylation (Otálvaro et al., 2010).

In order to investigate the demethylation of $4^{\prime}$-methoxycinnamic acid (2) and to check which of the two routes, $i$ or $i i$, is operating in $A$. preissii, $\left[2-{ }^{13} \mathrm{C}, 4^{\prime}-\mathrm{O}^{13} \mathrm{CH}_{3}\right]-2$ was synthesized; this compound contains $99 \%{ }^{13} \mathrm{C}$ enrichment in both positions, at $\mathrm{C}-2$ of the carbon skeleton and in the 4'-O-methyl group. The specific ${ }^{13} \mathrm{C}$ enrichment at C-2 was employed to verify that the C-9 phenylpropanoid skeleton had been incorporated through the established general biosynthetic pathway; the label of the $4^{\prime}$-O-methyl group was used to check for a possible 4'-O-demethylation step. Thus, after the incubation of $A$. preissii root cultures with $\left[2-{ }^{13} \mathrm{C}, 4^{\prime}-\mathrm{O}^{13} \mathrm{CH}_{3}\right]-2$, a part of the substrate was isolated from this feeding experiment again and analyzed by ${ }^{1} \mathrm{H}$ NMR and HRESIMS to see what part of it was labeled. The integrals of the central and ${ }^{13} \mathrm{C}$ satellite signals of $\mathrm{H}-2\left(\delta\right.$ 6.36) and the $\mathrm{OCH}_{3}$ signal $(\delta$ 3.85 ) in the ${ }^{1} \mathrm{H}$ NMR spectrum (Fig. 1C, D) showed $89 \%{ }^{13} \mathrm{C}$ in 

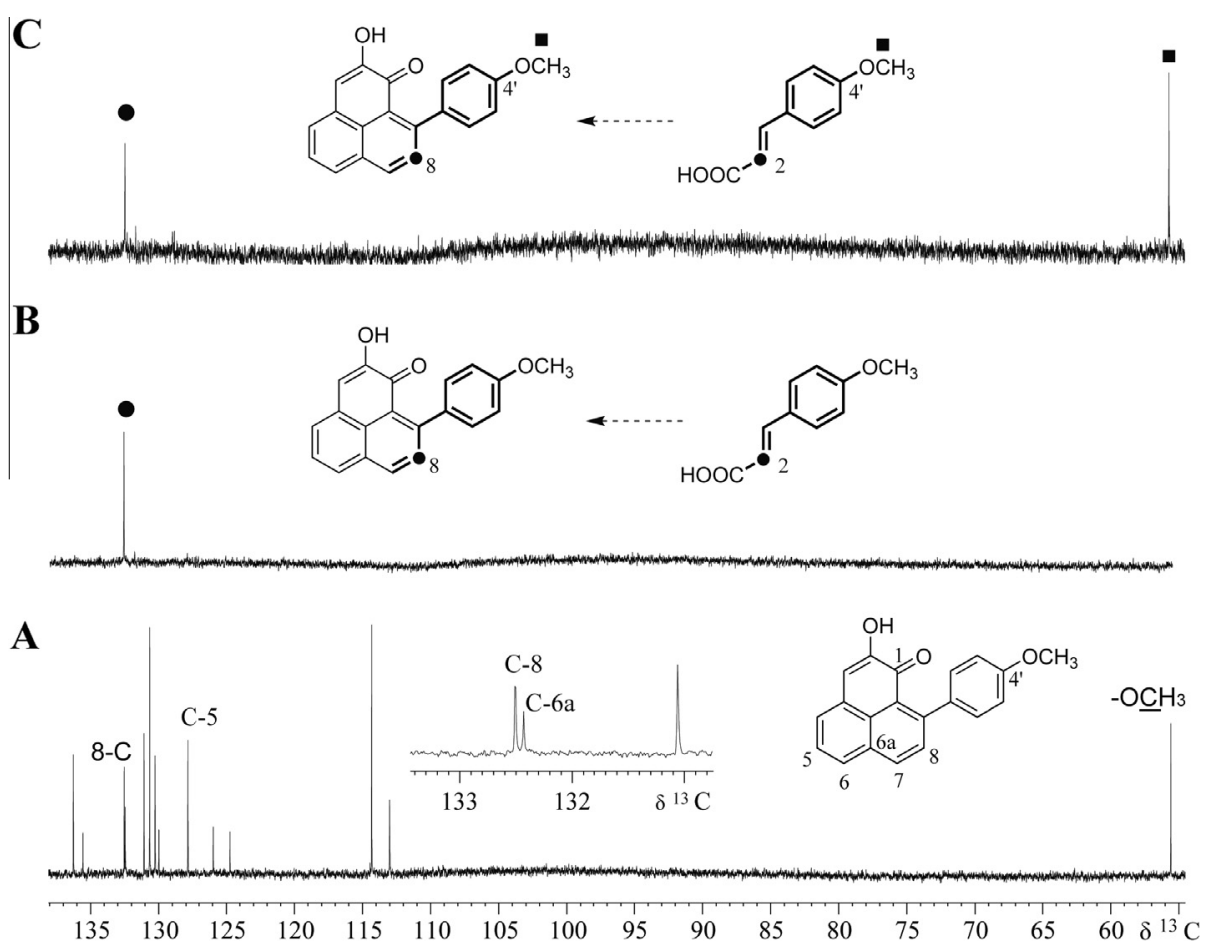

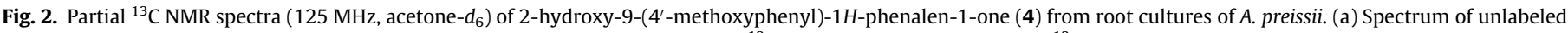

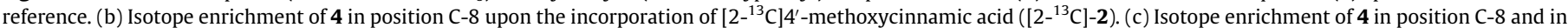

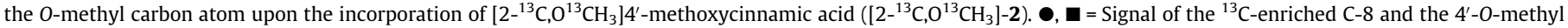
group, respectively.

Table 2

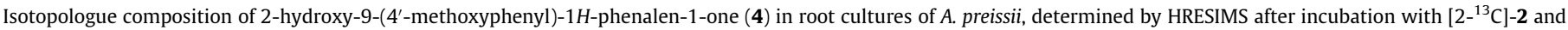
$\left[2-{ }^{13} \mathrm{C}_{2} \mathrm{O}^{13} \mathrm{CH}_{3}\right]-2$, respectively.

\begin{tabular}{|c|c|c|c|c|c|c|c|}
\hline \multirow[t]{3}{*}{ Formula } & \multirow{3}{*}{$\begin{array}{l}m / z[\mathrm{M}+\mathrm{H}]^{+} \\
\text {(calcd.) }\end{array}$} & \multicolumn{6}{|c|}{ Isotopologue analysis of compound $\mathbf{4}$ after incorporation of } \\
\hline & & \multicolumn{2}{|c|}{ Unlabeled 2 (reference) } & \multicolumn{2}{|l|}{$\left[2-{ }^{13} \mathrm{C}\right]-2$} & \multicolumn{2}{|c|}{$\left[2-{ }^{13} \mathrm{C}_{2} \mathrm{O}^{13} \mathrm{CH}_{3}\right]-2$} \\
\hline & & $\begin{array}{l}m / z[\mathrm{M}+\mathrm{H}]^{+} \\
\text {(found) }\end{array}$ & $\begin{array}{l}\text { Relative abundance } \\
(\%)\end{array}$ & $\begin{array}{l}m / z[\mathrm{M}+\mathrm{H}]^{+} \\
\text {(found) }\end{array}$ & $\begin{array}{l}\text { Relative abundance } \\
(\%)\end{array}$ & $\begin{array}{l}m / z[\mathrm{M}+\mathrm{H}]^{+} \\
\text {(found) }\end{array}$ & $\begin{array}{l}\text { Relative abundance } \\
(\%)\end{array}$ \\
\hline $\mathrm{C}_{20} \mathrm{H}_{15} \mathrm{O}_{3}^{+}$ & 303.1021 & 303.1016 & 80.3 & 303.1018 & 33.6 & 303.1019 & 35.9 \\
\hline $\mathrm{C}_{19}{ }^{13} \mathrm{CH}_{15} \mathrm{O}_{3}^{+}$ & 304.1055 & 304.1051 & 17.6 & 304.1053 & 53.7 & 304.1051 & 7.5 \\
\hline $\mathrm{C}_{18}{ }^{13} \mathrm{C}_{2} \mathrm{H}_{15} \mathrm{O}_{3}^{+}$ & 305.1088 & 305.1084 & 1.9 & 305.1085 & 12.3 & 305.1086 & 45.9 \\
\hline $\mathrm{C}_{17}{ }^{13} \mathrm{C}_{3} \mathrm{H}_{15} \mathrm{O}_{3}^{+}$ & 306.1122 & 306.1118 & 0.2 & 306.1120 & 0.4 & 306.1118 & 10.7 \\
\hline
\end{tabular}

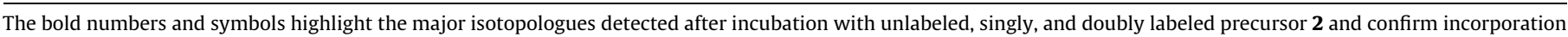
into 4 .

each of the two labeled positions, thus ruling out the possibility that the label in the $\mathrm{OCH}_{3}$ group was lost through a hypothetical demethylation/remethylation mechanism (Fig. 3). The isotope enrichment determined by ${ }^{1} \mathrm{H}$ NMR was in good agreement with that found for the abundance of the double-labeled isotopologue $\left[2-{ }^{13} \mathrm{C}, 4^{\prime}-\mathrm{O}^{13} \mathrm{CH}_{3}\right]-2$ of $84.4 \%$ found by HRESIMS (Table 3), although no single labeled isotopologues $\left[2-^{13} \mathrm{C}\right]-2$ and $\left[4^{\prime}-\mathrm{O}^{13} \mathrm{CH}_{3}\right]-2$ were detected.

As expected, the administration of $\left[2-{ }^{13} \mathrm{C}, 4^{\prime}-\mathrm{O}^{13} \mathrm{CH}_{3}\right]-2$ to the root cultures of $A$. preissii also resulted in the formation of metabolite 4, which was isolated and analyzed by NMR and HRESIMS. The ${ }^{13} \mathrm{C}$ NMR spectrum of $\left[2-{ }^{13} \mathrm{C}, 44^{\prime}-\mathrm{O}^{13} \mathrm{CH}_{3}\right]-4$ obtained from this experiment displayed two equally enhanced signals at $\delta 132.6$ and $\delta 55.6$, corresponding to an identical degree of ${ }^{13} \mathrm{C}$ enrichment at $\mathrm{C}-8$ and $4^{\prime}-\mathrm{OCH}_{3}$ (Fig. 2, panel c); this enrichment proved that the intact 4'-methoxycinnamic acid was incorporated as a unit into phenylphenalenone 4. Additionally, the isotopologue analysis by HRESIMS showed $45.9 \%$ relative abundance of the doubly ${ }^{13} \mathrm{C}$ - labeled isotopologue (Table 2). Hence, route $i$ in Fig. 3 represents the actual biosynthetic pathway of this metabolite.

\section{Conclusions}

Biosynthetic precursor-product relationships have been demonstrated in A. preissii between ferulic acid (1) and musanolone $F(3)$ and between $4^{\prime}$-methoxycinnamic acid (2), which is a rare phenylpropanoid, and 4 '-methoxyanigorufone (4). This finding clearly shows that in root cultures of this plant the substitution pattern at the lateral phenyl ring (ring D) of phenylphenalenones reflects the existence of the corresponding phenylpropanoids in the plant tissue. $4^{\prime}$-Methoxyanigorufone (4) is reported here for the first time as a natural product. The involvement of $4^{\prime}$ methoxycinnamic acid (2) in the phenylphenalenone biosynthesis represents an extension of the general phenylpropanoid pathway (Noel et al., 2005; Vogt, 2010). Thus, route $i$ (Fig. 3) requires a new CoA ligase or an additional function for a promiscuous 


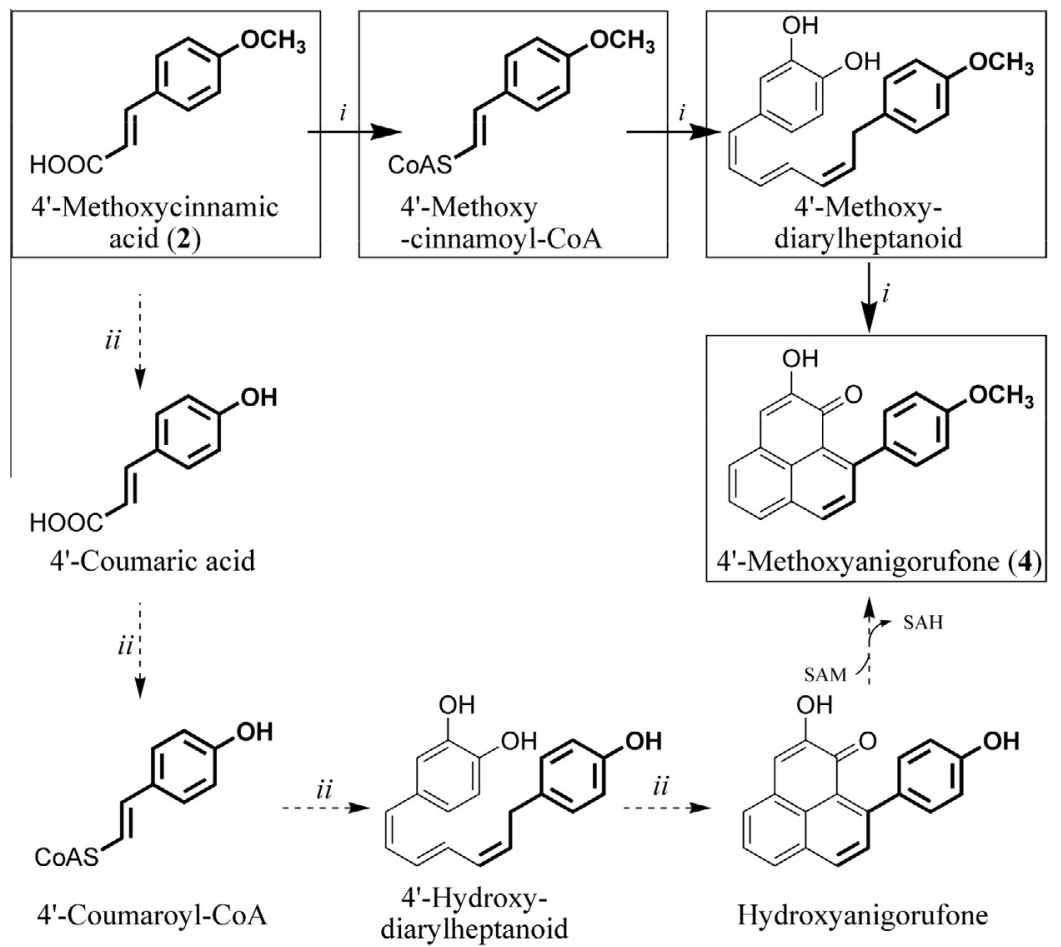

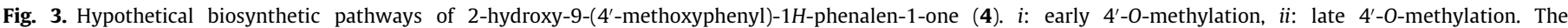
phenylpropanoid unit is highlighted in bold. SAM: S-adenosyl-L-methionine; SAH: $S$-adenosylhomocysteine.

Table 3

Isotopologue composition of $4^{\prime}$-methoxycinnamic acid (2) determined by HRESIMS. The isotopologue mixture of $\mathbf{2}$ was isolated after feeding experiments to in vitro root cultures of A. preissii and compared with the data from untreated root cultures of the same plant (control).

\begin{tabular}{|c|c|c|c|c|c|}
\hline \multirow[t]{3}{*}{ Formula } & \multirow{3}{*}{$\begin{array}{l}m / z \\
{[\mathrm{M}+\mathrm{H}]^{+}} \\
\text {(calcd.) }\end{array}$} & \multicolumn{4}{|c|}{ Isotopologue analysis of compound $\mathbf{2}$ isolated from } \\
\hline & & \multicolumn{2}{|c|}{ Control plant } & \multicolumn{2}{|c|}{$\begin{array}{l}\text { After incubation with } \\
{\left[2-{ }^{13} \mathrm{C}_{2} \mathrm{O}^{13} \mathrm{CH}_{3}\right]-2}\end{array}$} \\
\hline & & $\begin{array}{l}m / z \\
{[\mathrm{M}+\mathrm{H}]^{+}} \\
\text {(found) }\end{array}$ & $\begin{array}{l}\text { Relative } \\
\text { abundance } \\
(\%)\end{array}$ & $\begin{array}{l}m / z \\
{[\mathrm{M}+\mathrm{H}]^{+}} \\
\text {(found) }\end{array}$ & $\begin{array}{l}\text { Relative } \\
\text { abundance } \\
(\%)\end{array}$ \\
\hline $\mathrm{C}_{10} \mathrm{H}_{9} \mathrm{O}_{3}^{-}$ & 177.0557 & 177.0551 & 96.3 & 177.0553 & 14.2 \\
\hline $\mathrm{C}_{9}{ }^{13} \mathrm{CH}_{9} \mathrm{O}_{3}^{-}$ & 178.0591 & 178.0587 & 3.6 & 178.0585 & 0.1 \\
\hline $\mathrm{C}_{8}{ }^{13} \mathrm{C}_{2} \mathrm{H}_{9} \mathrm{O}_{3}^{-}$ & 179.0624 & 179.0622 & 0.1 & 179.0619 & 84.4 \\
\hline $\mathrm{C}_{7}{ }^{13} \mathrm{C}_{3} \mathrm{H}_{9} \mathrm{O}_{3}^{+}$ & 180.0658 & n.d. & n.d. & 180.0655 & 1.3 \\
\hline
\end{tabular}

n.d.: Not detected.

4-coumarate CoA-ligase. This work also demonstrates the potential power of isotopically labeled compounds as a tool, not only in the elucidation of biosynthetic pathways but also in the detection and quantification of naturally occurring minor metabolites.

\section{Experimental}

\subsection{General experimental procedures}

${ }^{1} \mathrm{H}$ NMR, ${ }^{13} \mathrm{C}$ NMR, ${ }^{1} \mathrm{H}-{ }^{1} \mathrm{H}$ COSY, HMBC, and HSQC spectra were measured on a Bruker Avance 500 NMR spectrometer (Bruker Biospin, Karlsruhe, Germany), operating at $500.13 \mathrm{MHz}$ for ${ }^{1} \mathrm{H}$ and $125.75 \mathrm{MHz}$ for ${ }^{13} \mathrm{C}$. A TCI cryoprobe $(5 \mathrm{~mm})$ was used to measure spectra at $300 \mathrm{~K}$. Tetramethyl silane was used as an internal standard for referencing ${ }^{1} \mathrm{H}$ and ${ }^{13} \mathrm{C}$ NMR spectra. Electrospray ionization mass spectra (ESIMS) and LC-ESIMS were recorded on a Bruker Esquire 3000 ion trap mass spectrometer (Bruker
Daltonics, Bremen, Germany). HRESIMS was recorded on a UPLCMS/MS system consisting of an Ultimate 3000 series RSLC (Dionex, Idstein, Germany) system, and an Orbitrap mass spectrometer (Thermo Fisher Scientific, Bremen, Germany). Analytical and semipreparative HPLC was performed on an Agilent series HP1100 (binary pump G1312A; auto sampler G1367A; diode array detector G1315A; connected to fraction collector Advantec CHF122SB) using a LiChrospher RP18e column $(5 \mu \mathrm{m}$, $250 \times 10 \mathrm{~mm}$ ) and a linear gradient $\mathrm{MeOH}-0.1 \%$ aq. trifluoroacetic acid from 35\% to $100 \%$ in $25 \mathrm{~min}$ (flow rate $0.8 \mathrm{~mL} / \mathrm{min}$; monitoring wavelength $254 \mathrm{~nm}$ ). The UV spectra were recorded by the DAD during analytical HPLC.

\subsection{Plant material}

Sterile root cultures of $A$. preissii L. and W. thyrsiflora Burm. were established as previously described (Hölscher and Schneider, 1997) and maintained in liquid MS medium $(100 \mathrm{~mL})$ in conical flasks $(300 \mathrm{~mL})$ on a gyratory shaker $(85 \mathrm{rpm})$ at $23^{\circ} \mathrm{C}$ under permanent light conditions $\left(4.4 \mu \mathrm{mol} \mathrm{m}{ }^{-2} \mathrm{~s}^{-1}\right)$. Three days before the precursor was administered, the cultured roots were transferred to fresh medium.

\subsection{Reagents and the chemical synthesis of the ${ }^{13} \mathrm{C}$-labeled precursors}

The $\left[2-{ }^{13} \mathrm{C}\right]$ hydroxycinnamic acids $\left(\left[2-{ }^{13} \mathrm{C}\right]\right.$ ferulic acid $\left(\left[2-{ }^{13} \mathrm{C}\right]-\right.$ 1), $\left[2-{ }^{13} \mathrm{C}\right]$ isoferulic acid, $\left[2-{ }^{13} \mathrm{C}\right] 4-$ methoxycinnamic acid $\left(\left[2-{ }^{13} \mathrm{C}\right]-\right.$ 2), $\left[2-{ }^{13} \mathrm{C}\right] 4$-coumaric acid and $\left[2-{ }^{13} \mathrm{C}\right] 3,4$-methylenedioxy cinnamic acid) were prepared from the corresponding substituted benzaldehyde $(0.33 \mathrm{mmol}$; Sigma-Aldrich, $\geqslant 95.0 \%)$ (vanillin, isovanillin, anisaldehyde, 4-hydroxybenzaldehyde, piperonal) with $\left[2-{ }^{13} \mathrm{C}\right]$ malonic acid $\left(99 \%{ }^{13} \mathrm{C} ; 0.72 \mathrm{mmol}\right.$; Deutero $\mathrm{GmbH}$, Kastellaun, Germany) in a Knoevenagel reaction. The ${ }^{13} \mathrm{C}$-methylated $\left[2-{ }^{13} \mathrm{C}, 4^{\prime}-\mathrm{O}^{13} \mathrm{CH}_{3}\right] 4$-methoxycinnamic acid $\left(\left[2-{ }^{13} \mathrm{C}, 4^{\prime}-\right.\right.$ 
$\left.\left.\mathrm{O}^{13} \mathrm{CH}_{3}\right]-2\right)$ was synthesized by refluxing $\left[2-{ }^{13} \mathrm{C}\right] 4$-coumaric acid (10 mg, $\quad 0.061 \mathrm{mmol}), \quad \mathrm{K}_{2} \mathrm{CO}_{3} \quad(10 \mathrm{mg}), \quad$ and ${ }^{13} \mathrm{CH}_{3} \mathrm{I} \quad(20 \mu \mathrm{L}$, $0.32 \mathrm{mmol}, 99$ atom $\%{ }^{13} \mathrm{C}$ Sigma-Aldrich) in acetone $(5 \mathrm{~mL})$ for $4 \mathrm{~h}$ in order to yield $8.7 \mathrm{mg}$ (79\%) of the desired compound.

\subsection{Feeding experiments, extraction and isolation of phenylphenalenones}

Each ${ }^{13} \mathrm{C}$-labeled compound $(10 \mu \mathrm{mol})$ was dissolved in an EtOH: $\mathrm{H}_{2} \mathrm{O} 4: 1$ solution ( $1 \mathrm{~mL}$ ) and passed through a membrane filter $(0.1 \mu \mathrm{m}$ diameter) before being administered to the root culture. The incubation time was $4 \mathrm{~d}$; afterwards, the roots (ca. $20 \mathrm{~g}$ fresh weigh) were frozen in liquid $\mathrm{N}_{2}$, ground and extracted with methanol at room temperature for $1 \mathrm{~h}(3 \times 100 \mathrm{~mL})$. The solvent was removed by evaporation under vacuum pressure $\left(<40^{\circ} \mathrm{C}\right)$, and the crude extract was fractionated by partitioning between $n$-hexane- $\mathrm{H}_{2} \mathrm{O}, \mathrm{CH}_{2} \mathrm{Cl}_{2}-\mathrm{H}_{2} \mathrm{O}$ and EtOAc- $\mathrm{H}_{2} \mathrm{O}$. The ${ }^{13} \mathrm{C}$ NMR labeling experiment was used to identify metabolites specifically enriched by the incorporation of the labeled precursor. Musanolone $\mathrm{F}$ (3, $R_{\mathrm{t}} 20.9 \mathrm{~min}$ ) and 2-hydroxy-9-(4'-methoxyphenyl)-1H-phenalen1-one $\left(4, R_{\mathrm{t}} 23.9 \mathrm{~min}\right)$, the products derived from successful incorporation, were isolated by semipreparative HPLC as described above. The analytical data of compound $\mathbf{3}$ exactly matched those of musanolone $\mathrm{F}$ available in our in-house database.

\subsection{2-Hydroxy-9-(4'-methoxyphenyl)-1H-phenalen-1-one (4)}

The ${ }^{1} \mathrm{H}$ - and ${ }^{13} \mathrm{C}$ NMR spectra of compound 4 resembled that of hydroxyanigorufone, which was previously reported from $A$. preissii root cultures (Hölscher and Schneider, 1997). The only exception was an additional singlet in the ${ }^{1} \mathrm{H}$ NMR spectrum $(\delta 3.89)$ and a corresponding signal in the ${ }^{13} \mathrm{C}$ NMR spectrum ( $\delta$ 55.6), suggesting an $O$-methyl group was attached to one of the hydroxyl groups at 2-OH or $4^{\prime}-\mathrm{OH}$. An HMBC cross-peak between the ${ }^{1} \mathrm{H}$ NMR signal of the $O$-methyl group and $C-4^{\prime}(\delta 160.3)$ of the lateral phenyl ring clearly indicated the methoxy group was attached to the $p$-position of ring D. ${ }^{1} \mathrm{H},{ }^{1} \mathrm{H}-\mathrm{COSY}$ and HSQC spectra, in addition to $\mathrm{HMBC}$ data, allowed all ${ }^{1} \mathrm{H}$ and ${ }^{13} \mathrm{C}$ chemical shifts to be assigned. Based on the above NMR data and combined with HRESIMS (Table 2), the structure of compound 4 was elucidated as 2-hydroxy-9-(4'-methoxyphenyl)- $1 \mathrm{H}$-phenalen-1-one. ${ }^{1} \mathrm{H}$ NMR $\left(500 \mathrm{MHz}\right.$, acetone- $\left.d_{6}\right): \delta 8.39(1 \mathrm{H}, \mathrm{d}, J=8.3 \mathrm{~Hz}, \mathrm{H}-7), 8.08(1 \mathrm{H}, \mathrm{d}$, $J=8.2 \mathrm{~Hz}, \mathrm{H}-4), 7.87(1 \mathrm{H}, \mathrm{d}, J=7.2 \mathrm{~Hz}, \mathrm{H}-6), 7.68(1 \mathrm{H}, \mathrm{dd}, J=8.2$, $7.2 \mathrm{~Hz}, \mathrm{H}-5), 7.64(1 \mathrm{H}, \mathrm{d}, J=8.3 \mathrm{~Hz}, \mathrm{H}-8), 7.34$ (2H, d-like, $\left.J=8.8 \mathrm{~Hz}, \mathrm{H}-2^{\prime} / 6^{\prime}\right), 7.18(1 \mathrm{H}, \mathrm{s}, \mathrm{H}-3), 7.02(2 \mathrm{H}, \mathrm{d}-$ like, $J=8.8 \mathrm{~Hz}$, $\left.\mathrm{H}-3^{\prime} / 5^{\prime}\right)$, $3.89\left(3 \mathrm{H}, \mathrm{s}, 4^{\prime}-\mathrm{OCH}_{3}\right) ;{ }^{13} \mathrm{C}$ NMR $\left(125 \mathrm{MHz}\right.$, acetone- $\left.d_{6}\right): \delta$ 180.9 (C-1), 160.3 (C-4'), 151.5 (C-2), 149.3 (C-9), 136.3 (C-7), $135.6\left(\mathrm{C}-1^{\prime}\right), 132.6(\mathrm{C}-8), 132.5$ (C-6a), 131.1 (C-6), 130.7 (C2'/6'), 130.3 (C-4), 130.0 (C-3a), 127.9 (C-5), 126.0 (C-9b), 124.8 (C-9a), $114.4\left(\mathrm{C}-3^{\prime} / 5^{\prime}\right), 113.1(\mathrm{C}-3), 55.6\left(4^{\prime}-\mathrm{OCH}_{3}\right)$. UV (MeOH$\left.\mathrm{H}_{2} \mathrm{O}\right): \lambda_{\max } 265,315,371,420 \mathrm{~nm}$.

\section{Acknowledgments}

We thank COLCIENCIAS (Colombia) for a scholarship to W.H., the Max Planck Institute for Chemical Ecology for financial support and Emily Wheeler for editorial assistance.

\section{Appendix A. Supplementary data}

Supplementary data associated with this article can be found, in the online version, at http://dx.doi.org/10.1016/j.phytochem.2015. 07.017.

\section{References}

Blokhina, O., Virolainen, E., Fagerstedt, K.V., 2003. Antioxidants, oxidative damage and oxygen deprivation stress: a review. Ann. Bot. 91, 179-194.

Brewer, M.S., 2011. Natural antioxidants: sources, compounds, mechanisms of action, and potential applications. Compr. Rev. Food Sci. Food Saf. 10, 221-247.

Buanafina, M.M.D., 2009. Feruloylation in grasses: current and future perspectives. Mol. Plant 2, 861-872.

Chen, Y.C., Liao, C.H., Chen, I.S., 2007. Lignans, an amide and anti-platelet activities from Piper philippinum. Phytochemistry 68, 2101-2111.

Cooke, R.G., Dagley, I.J., 1978. Coloring matters of Australian plants. 20. Synthesis of hydroxyanigorufone and related phenalenones. Aust. J. Chem. 31, 193-197.

Duque, L., Restrepo, C., Saez, J., Gil, J., Schneider, B., Otálvaro, F., 2010. Synthesis of musafluorone: a naphthoxanthenone isolated from Musa acuminata. Tetrahedron Lett. 51, 4640-4643.

Fang, J.J., Paetz, C., Hölscher, D., Munde, T., Schneider, B., 2011. Phenylphenalenones and related natural products from Wachendorfia thyrsiflora L. Phytochem. Lett. 4, 203-208.

Fang, J.J., Kai, M., Schneider, B., 2012. Phytochemical profile of aerial parts and roots of Wachendorfia thyrsiflora L. studied by LC-DAD-SPE-NMR. Phytochemistry 81, 144-152.

Funk, C., Brodelius, P.E., 1990. Phenylpropanoid metabolism in suspension-cultures of Vanilla planifolia Andr. 3. Conversion of 4-methoxycinnamic acids into 4hydroxybenzoic Acids. Plant Physiol. 94, 102-108.

Hidalgo, W., Duque, L., Saez, J., Arango, R., Gil, J., Rojano, B., Schneider, B., Otálvaro, F., 2009. Structure activity relationship in the interaction of substituted perinaphthenones with Mycosphaerella fijiensis. J. Agric. Food Chem. 57, 74177421.

Hölscher, D., Schneider, B., 1995a. The biosynthetic origin of the central one-carbon unit of phenylphenalenones in Anigozanthos preissii. Nat. Prod. Lett. 7, 177-182.

Hölscher, D. Schneider, B., 1995b. A diarylheptanoid intermediate in the biosynthesis of phenylphenalenones in Anigozanthos preissii. J. Chem. Soc. Chem. Commun., 525-526

Hölscher, D., Schneider, B., 1997. Phenylphenalenones from root cultures of Anigozanthos preissii. Phytochemistry 45, 87-91.

Hölscher, D., Dhakshinamoorthy, S., Alexandrov, T., Becker, M., Bretschneider, T., Buerkert, A., Crecelius, A.C., De Waele, D., Elsen, A., Heckel, D.G., Heklau, H., Hertweck, C., Kai, M., Knop, K., Krafft, C., Maddula, R.K., Matthaus, C., Popp, J., Schneider, B., Schubert, U.S., Sikora, R.A., Svatoś, A., Swennen, R.L., 2014. Phenalenone-type phytoalexins mediate resistance of banana plants (Musa spp.) to the burrowing nematode Radopholus similis. Proc. Natl. Acad. Sci. U.S.A. $111,105-110$

Jitsaeng, K., Schneider, B., 2010. Metabolic profiling of Musa acuminata challenged with Sporobolomyces salmonicolor. Phytochem. Lett. 3, 84-87.

Kroon, P.A., Williamson, G., 1999. Hydroxycinnamates in plants and food: current and future perspectives. J. Sci. Food Agric. 79, 355-361.

Kuddus, M.R., Rumi, F., Kaisar, M.A., Hasan, C.M., Rashid, M.A., 2010. Trans-isoferulic acid from Curcuma longa. B. Latinoam. Caribe Pl. 9, 319-321.

Liu, I.M., Chi, T.C., Hsu, F.L., Chen, C.F., Cheng, J.T., 1999. Isoferulic acid as active principle from the rhizoma of Cimicifuga dahurica to lower plasma glucose in diabetic rats. Planta Med. 65, 712-714.

Luis, J.G., Fletcher, W.Q., Echeverri, F., Grillo, T.A., 1994. Phenalenone-type phytoalexins from Musa acuminata. Synthesis of 4-phenylphenalenones. Tetrahedron 50, 10963-10970.

Munde, T., Brand, S., Hidalgo, W., Maddula, R.K., Svatoś, A., Schneider, B., 2013. Biosynthesis of tetraoxygenated phenylphenalenones in Wachendorfia thyrsiflora. Phytochemistry 91, 165-176.

Noel, J.P., Austin, M.B., Bomati, E.K., 2005. Structure-function relationships in plant phenylpropanoid biosynthesis. Curr. Opin. Plant Biol. 8, 249-253.

Opitz, S., Schneider, B., 2003. Oxidative biosynthesis of phenylbenzoisochromenones from phenylphenalenones. Phytochemistry 62, 307-312.

Opitz, S., Otálvaro, F., Echeverri, F., Quiñones, W., Schneider, B., 2002. Isomeric oxabenzochrysenones from Musa acuminata and Wachendorfia thyrsiflora. Nat. Prod. Lett. 16, 335-338.

Otálvaro, F., Nanclares, J., Vasquez, L.E., Quiñones, W., Echeverri, F., Arango, R., Schneider, B., 2007. Phenalenone-type compounds from Musa acuminata var. "Yangambi km 5" (AAA) and their activity against Mycosphaerella fijiensis. J. Nat. Prod. 70, 887-890.

Otálvaro, F., Jitsaeng, K., Munde, T., Echeverri, F., Quiñones, W., Schneider, B., 2010. O-Methylation of phenylphenalenone phytoalexins in Musa acuminata and Wachendorfia thyrsiflora. Phytochemistry 71, 206-213.

Schmitt, B., Schneider, B., 2001. Phenylpropanoid interconversion in Anigozanthos preissii observed by high-performance liquid chromatography-nuclear magnetic resonance spectroscopy. Phytochem. Anal. 12, 43-47.

Schmitt, B., Hölscher, D., Schneider, B., 2000. Variability of phenylpropanoid precursors in the biosynthesis of phenylphenalenones in Anigozanthos preissii. Phytochemistry 53, 331-337.

Schneider, B., Gershenzon, J., Graser, G., Hölscher, D., Schmitt, B., 2003. Onedimensional ${ }^{13} \mathrm{C}$ NMR and HPLC- ${ }^{1} \mathrm{H}$ NMR techniques for observing carbon-13 and deuterium labelling in biosynthetic studies. Phytochem. Rev., 31-43

Sobolev, V.S., Horn, B.W., Potter, T.L., Deyrup, S.T., Gloer, J.B., 2006. Production of stilbenoids and phenolic acids by the peanut plant at early stages of growth. J. Agric. Food Chem. 54, 3505-3511.

Vogt, T., 2010. Phenylpropanoid biosynthesis. Mol. Plant 3, 2-20. 